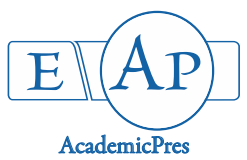

Pathak AR and Joshi AG (2021)

Notulae Scientia Biologicae

Volume 13, Issue 2, Article number 10831

DOI: $10.15835 / \mathrm{nsb} 13210831$

Research Article

\title{
Regeneration of Hemidesmus indicus (L.) R. Br. using in vitro nodes: an alternative method for efficient multiplication of shoots
}

\author{
Ashutosh R. PATHAK, Aruna G. JOSHI* \\ The Maharaja Sayajirao University of Baroda, Faculty of Science, Department of Botany, Vadodara- 390002, Gujarat, India; \\ ashutosh.pathak87@gmail.com; aruna.joshi-botany@msubaroda.ac.in (*correspondingauthor)
}

\begin{abstract}
In vivo nodes of Hemidesmus indicus (L.) R. Br. induced healthy multiple shoots with branching in our earlier studies and thus in the present study, potency of in vitro nodes to regenerate shoots was evaluated. In vitro nodes were excised from eight-week-old shoots and placed in Murashige and Skoog's (MS) medium fortified with sucrose (3\%) and different concentrations of 6-benzyladenine (BA) and kinetin (Kn). After eight weeks, optimum of $5.42 \pm 0.36$ shoots with $100 \%$ response were regenerated in medium supplemented with $\mathrm{BA}(10 \mu \mathrm{M})$ and $\mathrm{Kn}(5 \mu \mathrm{M})$. These healthy shoots were placed in full, half and quarter strengths of liquid MS medium fortified with sucrose (1\%) and $\alpha$-naphthaleneacetic acid (NAA, 1-25 $\mu \mathrm{M}$ ) for rooting. Among all the strengths of MS medium, full strength MS medium having $8 \mu \mathrm{M}$ NAA formed maximum of $3.42 \pm 0.55$ roots ( $91.67 \%$ response) within four weeks. The protocol is in continuation with earlier study and it was confirmed that a single in vivo nodal explant can regenerate around 385 healthy elongated shoots within 4 months, which will help in mass-propagation of the species.

Keywords: axillary shoots; clonal multiplication; cytokinins; medicinal plant; tissue culture

\section{Introduction}

Hemidesmus indicus (L.) R. Br. (Asclepiadaceae), commonly known as 'anantmool', is a slender, laticiferous, semi erect shrub widely used in Indian Systems of Medicine (Anonymous, 1997). The plant is prescribed for its properties to give longevity, rejuvenation and strengthening the bones and tissues and hence considered as 'Rasayana' drug (Puri, 2003). Traditionally the plant is used to cure scorpion sting and rat bite poisoning (Sharma et al., 1979) and also have uses to treat many ailments like blood diseases, diarrhoea, respiratory disorders, kidney and urinary disorders, skin diseases, syphilis and rheumatic fever (Nadkarni, 1989). The multipurpose medicinal attributes are because it has important secondary metabolites like lupeol, vanillin, rutin, 2-hydroxy-4-methoxybenzaldehyde and $\beta$-sitosterol (Chatterjee and Bhattacharya, 1955; Subramanian and Nair, 1968; Gupta et al., 1992; Nagarajan and Rao, 2003). National Medicinal Plants Board (NMPB) has reported $H$. indicus as one of the priority species because its annual requirement is $500-1000 \mathrm{MT}$ (Ved and Goraya, 2007). To fulfil this demand, H. indicus is extensively collected from natural habitats and its vegetative propagation is slow, due to which it has become endangered (Sreekumar et al., 2000). Thus, since last two decades it is being imported from other countries like Myanmar, Mexico and Morocco (Planning commission, 2000).
\end{abstract}

Received: 11 Oct 2020. Received in revised form: 08 May 2021. Accepted: 24 May 2021. Published online: 31 May 2021.

From Volume 13, Issue 1, 2021, Notulae Scientia Biologicae journal uses article numbers in place of the traditional method of continuous pagination through the volume. The journal will continue to appear quarterly, as before, with four annual numbers. 
Biotechnological tool like plant tissue culture is known to regenerate large number of plants in short time duration; and to achieve this leaf and nodal explants are mostly utilized. Nevertheless, regeneration through leaf explant is known to induce soma clonal variants and hence nodes are best suitable explants when the aim is to produce true-to-type plants (Pathak and Joshi, 2018). There are reports on H. indicus regeneration using nodal explants (Patnaik and Debata, 1996; Sreekumar et al., 2000; Misra et al., 2003; Saha et al., 2003; Shekhawat and Manokari, 2016; Pathak et al., 2017). However, the plant is a slow growing and sparingly branched in wild (Sreekumar et al., 2000) and hence use of nodal explant for plant regeneration may increase the threat on its population. George (1996) has depicted that the explants derived from shoot cultures have an early and greater capacity for regeneration due to juvenile nature as compared to in vivo plants. The utilization of in vitro nodes as an alternative to in vivo nodal explants for generating clonal plants has been reported in many endangered species (Baskaran and Jayabalan, 2005; Loganathan and Bai, 2014), whereas in H. indicus only few reports are documented (Sreekumar et al., 2000; Nagahatenna and Peiris, 2007). In previous study on in vivo nodal explants it was observed that the axillary buds of in vitro shoots had a tendency to form branches when grown in cytokinin fortified media (Pathak et al., 2017).

Thus, the present study was focuses on the potency of in vitro nodes to form shoots through which clonal multiplication of $H$. indicus can be achieved and it will help in mass-propagation.

\section{Materials and Methods}

\section{Plant material and culture medium for shoot regeneration}

Healthy twigs of $H$. indicus were collected from the Botanical Garden of The M.S. University of Baroda. Nodal explants were excised, washed under running tap water for $1 \mathrm{~h}$, surface sterilized and inoculated in earlier optimized media for shoot culture establishment i.e. MS (Murashige and Skoog, 1962) medium fortified with 6-benzyladenine (BA, $10 \mu \mathrm{M})$ and kinetin $(\mathrm{Kn}, 5 \mu \mathrm{M})$ (Pathak et al., 2017). After eight weeks, these shoots were harvested from mother explant, all the leaves were trimmed off and in vitro nodes $(2-3 \mathrm{~cm}$ long) were used as an explant for the present study. They were inoculated vertically into MS medium fortified with sucrose (3\%) (SRL, Mumbai, India) and different concentrations of BA and Kn (5-20 $\mu \mathrm{M})$ (SRL, Mumbai, India).pH of the medium was adjusted to 5.80 using $\mathrm{NaOH} / \mathrm{HCl}(1 \mathrm{~N})$ and agar $(0.8 \%)$ (SRL, Mumbai, India) was used as the gelling agent. All the media were sterilized in autoclave at $121^{\circ} \mathrm{C}(15 \mathrm{psi})$ for $20 \mathrm{~min}$.

\section{In vitro rooting}

Healthy micro shoots ( 8 weeks old; $>3 \mathrm{~cm}$ in length) were excised, leaves were removed and dipped in sterile distilled water and bavistin solution $(0.01 \%)$ ( 1 min each). Different strengths (full, half, and quarter) of liquid MS medium fortified with sucrose (1\%) and various concentrations of $\alpha$-naphthaleneacetic acid (NAA; SRL, Mumbai, India) $(1-25 \mu \mathrm{M})$ was used as rooting media.

\section{Culture conditions}

All the cultures were kept in culture room and maintained at $26 \pm 2{ }^{\circ} \mathrm{C}$ under $16 / 8 \mathrm{~h}$ (dark/light) photoperiod at $40 \mu \mathrm{mol} / \mathrm{m}^{2} / \mathrm{s}$ provided by cool-white fluorescent lights (Philips India Ltd., India).

\section{Statistical analysis}

The values are given as mean and standard error (SE) from twelve replicates. All the means were analysed using ANOVA $(\alpha=0.05)$ and significant means were further analysed by Tukey's test using XLSTAT v2017.02. 


\section{Results and Discussion}

\section{Shoot regeneration}

In vitro nodes derived from eight-week-old shoot cultures were used as an explant for clonal multiplication in MS basal medium, which evoked a meagre response as it formed only $0.58 \pm 0.22$ shoots (41.67\% response) (Table 1). Supplementing the medium with different concentration of BA (5-20 $\mu \mathrm{M})$ slightly increased the culture response and the shoot number was increased to $1.83 \pm 0.16$ (100\% response) when BA concentration reached to $10 \mu \mathrm{M}$. Further increase in concentrations to 15 and $20 \mu \mathrm{M}$ failed to enhance the number of shoots. When BA was replaced with $\mathrm{Kn}$ in the medium it also resulted in a similar response as only $1.58 \pm 0.28$ shoots $(83.33 \%$ response) were recorded in media containing $10 \mu \mathrm{M}$ Kn (Table 1). Thus, both the cytokinins individually formed healthy axillary shoots, but they failed to induce multiples.

The response in terms of number of shoots was increased as the MS medium was augmented with both $\mathrm{BA}$ and $\mathrm{Kn}$ as it induced multiple shoots in most of the combinations. Eight weeks observations depicted that optimum $5.42 \pm 0.36$ shoots in $100 \%$ cultures were formed in medium supplemented with BA $(10 \mu \mathrm{M})$ and $\mathrm{Kn}(5 \mu \mathrm{M})$ (Table 1). In this combination the axillary bud beak was recorded within a week of inoculation (Figure 1A). This bud elongated and formed shoot during second week and simultaneously bud break from the opposite node was also observed (Figure 1B). These shoots started to elongate in third week and branching of shoots was occurred during fourth week (Figure 1C). At the end of four weeks the shoots were sub-cultured which further proliferated and multiplied till the end of eight weeks (Figure 1D). Thus, it was confirmed that in vitro buds, which were harvested after every eight weeks of culture period, retained the potency to form shoot cultures.

Table 1. Regeneration of shoots from in vitro nodes of $H$. indicus in presence of cytokinins ( 8 weeks)

\begin{tabular}{|c|c|c|c|}
\hline \multicolumn{2}{|c|}{ PGR $(\mu \mathrm{M})$} & \multirow{2}{*}{ No. of shoots/explant } & \multirow{2}{*}{ Response (\%) } \\
\hline BA & $\mathrm{Kn}$ & & \\
\hline 0 & 0 & $0.58 \pm 0.22 f$ & 41.67 \\
\hline 5 & 0 & $1.17 \pm 0.16 \mathrm{ef}$ & 91.67 \\
\hline 10 & 0 & $1.83 \pm 0.16 \mathrm{cdef}$ & 100 \\
\hline 15 & 0 & $1.42 \pm 0.18 \mathrm{def}$ & 91.67 \\
\hline 20 & 0 & $1.08 \pm 0.18 \mathrm{f}$ & 83.33 \\
\hline 0 & 5 & $0.83 \pm 0.16 \mathrm{f}$ & 75 \\
\hline 0 & 10 & $1.58 \pm 0.28 \mathrm{def}$ & 83.33 \\
\hline 0 & 15 & $1.33 \pm 0.30 \mathrm{def}$ & 83.33 \\
\hline 0 & 20 & $0.83 \pm 0.26 f$ & 58.33 \\
\hline 5 & 5 & $2.00 \pm 0.51 \mathrm{bcdef}$ & 58.33 \\
\hline 5 & 10 & $2.17 \pm 0.47 \mathrm{bcdef}$ & 66.67 \\
\hline 5 & 15 & $1.75 \pm 0.47 \mathrm{cdef}$ & 66.67 \\
\hline 5 & 20 & $1.08 \pm 0.32 \mathrm{f}$ & 50 \\
\hline 10 & 5 & $5.42 \pm 0.36 a$ & 100 \\
\hline 10 & 10 & $4.67 \pm 0.54 \mathrm{ab}$ & 100 \\
\hline 10 & 15 & $4.33 \pm 0.48 \mathrm{abc}$ & 91.67 \\
\hline 10 & 20 & $3.83 \pm 0.79$ abcde & 83.33 \\
\hline 15 & 5 & $3.92 \pm 0.61 \mathrm{abcd}$ & 83.33 \\
\hline 15 & 10 & $3.25 \pm 0.72$ abcdef & 75 \\
\hline 15 & 15 & $3.17 \pm 0.79$ abcdef & 75 \\
\hline 15 & 20 & $2.58 \pm 0.59 \mathrm{bcdef}$ & 75 \\
\hline 20 & 5 & $3.00 \pm 0.61 \mathrm{abcdef}$ & 83.33 \\
\hline 20 & 10 & $3.25 \pm 0.59$ abcdef & 75 \\
\hline 20 & 15 & $2.83 \pm 0.73$ abcdef & 66.67 \\
\hline 20 & 20 & $2.25 \pm 0.68$ bcdef & 50 \\
\hline
\end{tabular}

${ }^{*}$ Values represents mean \pm SE. Means $(\mathrm{n}=12)$ were subjected to ANOVA and means followed by same letter are not significantly different $(\mathrm{p} \leq 0.05)$ according to Tukey's test 
Beneficial effect of cytokinins in axillary shoot regeneration is mainly attributed due to their involvement in processes like promotion of cell division, expansion, regulation of shoot formation and its multiplication (Mok and Mok, 2001). Synergistic combination of BA and Kn evoked optimum regeneration in the present study and the shoot number obtained in this protocol was higher as compared to previous report on same plant (Nagahatenna and Peiris, 2007). The combined effect of BA and $\mathrm{Kn}$ is also reported for maximum axillary bud multiplication in $H$. indicus (Shekhawat and Manokari, 2016). Similarly, in other medicinal plants like Eclipta alba (Baskaran and Jayabalan, 2005), Vanilla planifolia (Abebe et al., 2009), Pogostemon cablin (Swamy et al., 2010) and Enicostema axillare (Loganathan and Bai, 2014) BA with Kn induced optimum shoots from in vitro nodes. Moreover, the potency of in vitro nodes to regenerate shoots was less as compared to in vivo nodal explants of the same plant (Patnaik and Debata, 1996; Sreekumar et al., 2000; Misra et al., 2003; Saha et al., 2003), it is also in contradiction to the earlier report which states that the potency of in vivo and in vitro nodes is the same (Sreekumar et al., 2000). But this study is in continuation of previous work in which from single node around 11 shoots were formed within eight weeks, each shoot had an average 7 nodes (Pathak et al., 2017). Thus approximately 77 in vitro nodes were obtained which were taken up for clonal multiplication of shoots and transferred to the media optimized in the present study. Total 5 shoots were regenerated with $100 \%$ response at the end of eight weeks which confirmed that around $77 \times 5=385$ shoots can be regenerated within 4 months from single in vivo nodal explant. Therefore, this method of using in vitro nodes for shoot regeneration is more efficient as compared to transferring of shoot clumps as reported for the same plant (Shekhawat and Manokari, 2016). The use of in vitro nodes will also resolve the problems reported for in vivo nodal explants of $H$. indicus such as leaf fall during culture multiplication, decrease in shoot number over successive passage, excessive callusing at the base of node and seasonal effect on regeneration frequency (Patnaik and Debata, 1996; Misra et al., 2003; Shekhawat and Manokari, 2016).

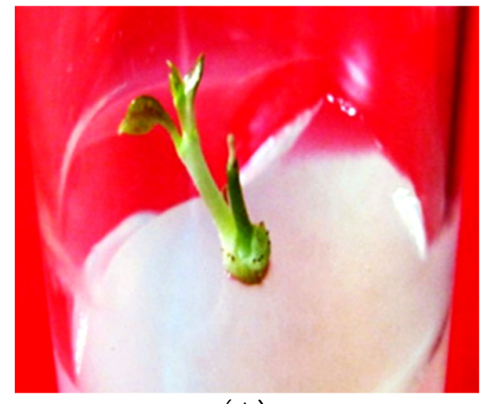

(A)

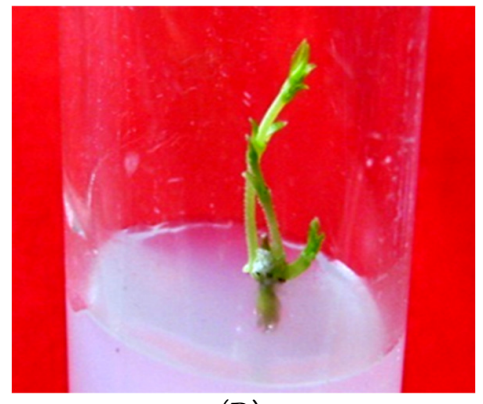

(B)

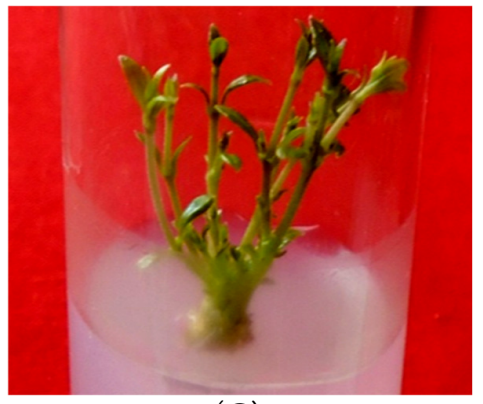

(C)

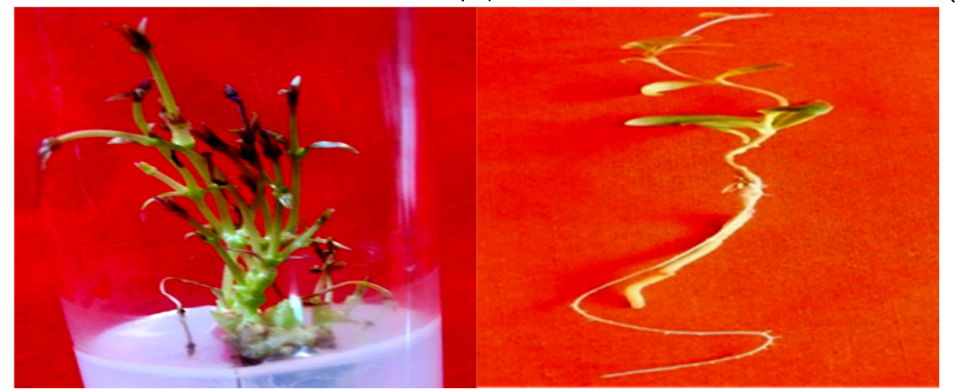

(D)

(E)

Figure 1. Shoot regeneration from in vitro nodes of $H$. indicus in $\mathrm{MS}+\operatorname{sucrose}(3 \%)+\mathrm{BA}(10 \mu \mathrm{M})+\mathrm{Kn}$ $(5 \mu \mathrm{M})$

(A) bud break after one week; (B) elongation of bud into shoots after two weeks; (C) multiple shoots with branching at the end of four weeks; (D) healthy elongated shoots after eight weeks; (E) rooting of microshoots in MS + sucrose $(1 \%)+$ NAA $(8 \mu \mathrm{M})$ after four weeks 


\section{In vitro rooting}

Elongated shoots were transferred to full, half and quarter strengths of liquid MS medium fortified with different NAA concentrations $(1-25 \mu \mathrm{M})$. In all the strengths, basal MS medium failed to induce roots and further fortifying it with NAA resulted in induction of roots. In full strength MS medium, lower levels of NAA $(1-4 \mu \mathrm{M})$ evoked poor response. The number of roots increased as the NAA level increased to 6 and $8 \mu \mathrm{M}$, and within four weeks optimum $3.42 \pm 0.55$ roots/shoot (91.67\% response) were formed at $8 \mu \mathrm{M}$ concentration in which $100 \%$ shoot survived (Figure 1E). Further increase in concentration adversely affected shoot survival as well as rooting. It was noted that reducing the strength of MS medium to half and quarter couldn't evoke a better rooting response (Table 2).

Table 2. Effect of different strengths of MS medium and concentrations of NAA on root formation in $H$. indicus shoots (4 weeks)

\begin{tabular}{|c|c|c|c|}
\hline NAA $(\mu \mathrm{M})$ & No. of roots/shoot ${ }^{*}$ & Response (\%) & Shoot survival (\%) \\
\hline \multicolumn{4}{|c|}{ MS } \\
\hline 0 & $0 \mathrm{~d}$ & 0 & 0 \\
\hline 1 & $0.33 \pm 0.14 \mathrm{~cd}$ & 33.33 & 25 \\
\hline 2 & $0.83 \pm 0.26 \mathrm{bcd}$ & 50 & 33.33 \\
\hline 4 & $1.17 \pm 0.28 \mathrm{bcd}$ & 66.67 & 66.67 \\
\hline 6 & $2.08 \pm 0.30 \mathrm{~b}$ & 83.33 & 83.33 \\
\hline 8 & $3.42 \pm 0.55 \mathrm{a}$ & 91.67 & 100 \\
\hline 10 & $1.33 \pm 0.40 \mathrm{bc}$ & 50 & 83.33 \\
\hline 15 & $1.08 \pm 0.38 \mathrm{bcd}$ & 41.67 & 66.67 \\
\hline 20 & $0.83 \pm 0.39 \mathrm{bcd}$ & 33.33 & 50 \\
\hline 25 & $0 \mathrm{~d}$ & 0 & 25 \\
\hline \multicolumn{4}{|c|}{$1 / 2 \mathrm{MS}$} \\
\hline 0 & $0 \mathrm{~d}$ & 0 & 0 \\
\hline 1 & $0.33 \pm 0.18 \mathrm{~cd}$ & 25 & 25 \\
\hline 2 & $0.42 \pm 0.22 \mathrm{~cd}$ & 25 & 25 \\
\hline 4 & $0.50 \pm 0.22 \mathrm{~cd}$ & 33.33 & 33.33 \\
\hline 6 & $0.67 \pm 0.30 \mathrm{~cd}$ & 33.33 & 41.67 \\
\hline 8 & $0.75 \pm 0.17 \mathrm{~cd}$ & 66.67 & 41.67 \\
\hline 10 & $0.92 \pm 0.36 \mathrm{bcd}$ & 41.67 & 50 \\
\hline 15 & $0.58 \pm 0.25 \mathrm{~cd}$ & 33.33 & 33.33 \\
\hline 20 & $0.17 \pm 0.11 \mathrm{~cd}$ & 16.67 & 16.67 \\
\hline 25 & $0 \mathrm{~d}$ & 0 & 0 \\
\hline \multicolumn{4}{|c|}{$1 / 4 \mathrm{MS}$} \\
\hline 0 & $0 \mathrm{~d}$ & 0 & 0 \\
\hline 1 & $0.17 \pm 0.16 \mathrm{~cd}$ & 8.33 & 16.67 \\
\hline 2 & $0.25 \pm 0.17 \mathrm{~cd}$ & 16.67 & 25 \\
\hline 4 & $0.33 \pm 0.18 \mathrm{~cd}$ & 25 & 25 \\
\hline 6 & $0.50 \pm 0.25 \mathrm{~cd}$ & 33.33 & 33.33 \\
\hline 8 & $0.42 \pm 0.18 \mathrm{~cd}$ & 33.33 & 41.67 \\
\hline 10 & $0.17 \pm 0.11 \mathrm{~cd}$ & 16.67 & 33.33 \\
\hline 15 & $0 \mathrm{~d}$ & 0 & 0 \\
\hline 20 & $0 \mathrm{~d}$ & 0 & 0 \\
\hline 25 & $0 \mathrm{~d}$ & 0 & 0 \\
\hline
\end{tabular}

${ }^{*}$ Values represents mean \pm SE. Means $(\mathrm{n}=12)$ were subjected to ANOVA and means followed by same letter are not significantly different $(\mathrm{p} \leq 0.05)$ according to Tukey's test. 
The MS media composition and auxins are two main factors which affects in vitro rooting (George and Sherrington, 1984). NAA has been reported to induce roots in Decalepis hamiltonii (Anitha and Pullaiah, 2002) and Stevia rebaudiana (Thiyagarajan and Venkatachalam, 2012). Similarly, in the present study rooting was achieved in full strength MS medium fortified with NAA $(8 \mu \mathrm{M})$. It was also observed that increase in its concentration adversely affected the rooting response and this may be due to biosynthesis of ethylene by higher concentration of auxins that hinders root formation (Riov and Yang, 1989; Taiz and Zeiger, 2003). However, the number of roots formed in presence of NAA is less as compared to indole-3-butyric acid (IBA) fortified medium (Pathak and Joshi, 2017). Martin (2002) documented that superiority of IBA is due to its slow movement and better degradation as compared to NAA, which makes it more available in the medium and increases the rooting. There are reports which stated the superiority of IBA over NAA in $H$. indicus (Shekhawat and Manokari, 2016) and other plants like Tylophora indica (Thomas and Philip, 2005) and Rubia cordifolia (Khadke et al., 2013).

\section{Conclusions}

In vitro nodes of $H$. indicus have potency to regenerate multiple shoots within eight weeks. Hence present study along with earlier developed protocol can generate around 385 shoots from single in vivo nodal explant within span of four months. Utilization of in vitro nodes from shoot cultures will help in continuous multiplication of shoots without hampering the wild plants. This protocol is efficient for mass-propagation and conservation of this endangered species as well as extraction of valuable secondary metabolites.

\section{Authors' Contributions}

AGJ and ARP: Designed and conceptualized the research. ARP: Performed the experimental work, analysed data and wrote the paper. AGJ: Supervised the work and revised the manuscript for important intellectual content. Both authors read and approved the final manuscript.

\section{Acknowledgements}

This work was supported by the University Grants Commission (UGC), New Delhi, India, under Research Fellowship in Science for Meritorious Students (UGC-BSR fellowship) scheme to ARP [grant number F.No.7-319/2011(BSR)]. Authors would also like to thank UGC, New Delhi, India, for providing DRS program to the Department.

\section{Conflict of Interests}

The authors declare that there are no conflicts of interest related to this article. 


\section{References}

Abebe Z, Mengesha A, Teressa A, Tefera W (2009). Efficient in vitro multiplication protocol for Vanilla planifolia using nodal explants in Ethiopia. African Journal of Biotechnology 8(24):6817-6821.

Anitha S, Pullaiah T (2002). In vitro propagation of Decalepis hamiltonii. Journal Tropical Medicinal Plants 3:227-232. Anonymous (1997). The wealth of India, raw materials, vol. III, V and X. CSIR, New Delhi, India.

Baskaran P, Jayabalan N (2005). An efficient micropropagation system for Eclipta alba-a valuable medicinal herb. In Vitro Cellular and Developmental Biology-Plant 41:532-539. https://doi.org/10.1079/IVP2005667

Chatterjee RC, Bhattacharya BK (1955). A note on the isolation of $\beta$-sitosterol from Hemidesmus indicus. Journal of the Indian Chemical Society 32:485-486.

George EF (1996). Plant propagation by tissue culture. Part 2: In practice. Exegetics Ltd., Edington, UK.

George EF, Sharrington PD (1984). Plant propagation by tissue culture: Handbook and directory of commercial laboratories. Exegetics Ltd., Edington, UK.

Gupta MM, Verma RK, Misra LN (1992). Terpenoids from Hemidesmus indicus. Phytochemistry 31:4036-4037. https://doi.org/10.1016/S0031-9422(00)97582-4

Khadke S, Rani S, Awad V, Meti N, Singh E, Kuvalekar A, Harsulkar A (2013). An improved protocol for in vitro regeneration of Rubia cordifolia L. via organogenesis. International Journal of Plant, Animal and Environmental Sciences 3(4):61-69.

Loganathan K, Bai VN (2014). High frequency in vitro plantlet regeneration and antioxidant activity of Enicostema axillare (Lam.) Raynal ssp. littoralis (Blume) Raynal: An important medicinal plant. Asian Pacific Journal of Reproduction 3(3):241-248. https://doi.org/10.1016/S2305-0500(14)60033-6

Martin KP (2002). Rapid propagation of Holostemma ada-kodien Schult., a rare medicinal plant, through axillary bud multiplication and indirect organogenesis. Plant Cell Reports 21:112-117. https://doi.org/10.1007/s00299002-0483-7

Misra N, Misra P, Datta SK, Mehrotra S (2003). Improvement in clonal propagation of Hemidesmus indicus R.Br. through adenine sulphate. Journal of Plant Biotechnology 5(4):239-244.

Mok DWS, Mok MC (2001). Cytokinin metabolism and action. Annual Review of Plant Physiology and Plant Molecular Biology 52:89-118. https://doi.org/10.1146/annurev.arplant.52.1.89

Murashige T, Skoog F (1962). A revised medium for rapid growth and bio-assays with tobacco tissue cultures. Physiologia Plantarum 15:473-497. https://doi.org/10.1111/j.1399-3054.1962.tb08052.x

Nadkarni AN (1989). Hemidesmus indicus R.Br. In: Nadkarni KM (Ed). Indian Materia Medica. Vol. 1. Popular Book Depot, Bombay, India pp 619-622.

Nagahatenna DSK, Peiris SE (2007). In vitro propagation of Hemidesmus indicus (L.) R. Br. (Iramusu) through nodal culture. Tropical Agricultural Research 19:181-192.

Nagarajan S, Rao LJ (2003). Determination of 2-hydroxy-4-methoxy benzaldehyde in roots of Decalepis hamiltonii (Wight \& Arn.) and Hemidesmus indicus R.Br. Journal of AOAC International 86(3):564-567.

Pathak A, Joshi A (2017). Indirect organogenesis from leaf explants of Hemidesmus indicus (L.) R. Br.: An important medicinal plant. Plant Biosystems 151(1):1-5. https://doi.org/10.1080/11263504.2015.1108938

Pathak A, Joshi A (2018). Soma clonal variation. In: Prasad BD, Sahni S, Kumar P, Siddiqui WM (Eds). Plant Biotechnology. Vol. 1: Principles, Techniques and Applications. Apple Academic Press (CRC Press), New York, USA pp 185-213. https://doi.org/10.1201/9781315213743

Pathak A, Joshi A, Shrivastava N, Sharma P (2017). Regeneration and chemical profiling in Hemidesmus indicus (L.) R. Br. South African Journal of Botany 173:413-420. https://doi.org/10.1016/j.sajb.2017.09.022

Patnaik J, Debata BK (1996). Micropropagation of Hemidesmus indicus (L.) R.Br. through axillary bud culture. Plant Cell Reports 15:427-430. https://doi.org/10.1007/BF00232069

Planning Commission (2000). Report of the task force on conservation and sustainable use of medicinal plants. Government of India, New Delhi.

Puri HS (2003). Rasayana: Ayurvedic herbs for longevity and rejuvenation. Taylor and Francis, London and New York. https://doi.org/10.1201/b12602

Riov J, Yang S (1989). Ethylene and auxin-ethylene interaction in adventitious root formation in mung bean (Vigna radiata) cuttings. Journal of Plant Growth Regulation 8(2):131-141. https://doi.org/10.1007/BF02025280 
Saha S, Mukhopadhyay MJ, Mukhopadhyay S (2003). In vitro clonal propagation through bud culture of Hemidesmus indicus (L.) R. Br: an important medicinal herb. Journal of Plant Biochemistry and Biotechnology 12:61-64. https://doi.org/10.1007/BF03263162

Sharma PK, Dhyani SK, Shankar V (1979). Some useful and medicinal plants of the district Dehradun and Siwalik. Journal of Scientific Research in Plant Medica 1:17-43.

Shekhawat MS, Manokari M (2016). In vitro regeneration frequency, micro-morphological studies and ex vitro rooting of Hemidesmus indicus (L.) R. Br.: a multipotent endangered climber. Indian Journal of Plant Physiology 21(2):151-160. https://doi.org/10.1007/s40502-016-0216-5

Sreekumar S, Seeni S, Pushpangadan P (2000). Micropropagation of Hemidesmus indicus for cultivation and production of 2-hydroxy-4-methoxy benzaldehyde. Plant Cell, Tissue and Organ Culture 62(3):211-218. https://doi.org/10.1023/A:1006486817203

Subramanian SS, Nair AGR (1968). Flavonoids of some Asclepiadaceous plants. Phytochemistry 7:1703-1704. https://doi.org/10.1016/S0031-9422(00)88630-6

Swamy MK, Balasubramanya S, Anuradha M (2010). In vitro multiplication of Pogostemon cablin Benth. through direct regeneration. African Journal of Biotechnology 9(14):2069-2075.

Taiz L, Zeiger E (2003). Auxins. In: Plant Physiology. Macmillan Publishing Co., New York, USA pp 623.

Thiyagarajan M, Venkatachalam P (2012). Large scale in vitro propagation of Stevia rebaudiana (Bert.) for commercial application: Pharmaceutically important and antidiabetic medicinal herb. Industrial Crops and Products 37:111-117. https://doi.org/10.1016/j.indcrop.2011.10.037

Thomas TD, Philip B (2005). Thidiazuron-induced high-frequency shoot organogenesis from leaf-derived callus of a medicinal climber, Tylophora indica (Burm. F.) Merrill. In Vitro Cellular and Developmental Biology-Plant 41:124-128. https://doi.org/10.1079/IVP2004575

Ved DK, Goraya GS (2007). Demand and supply of medicinal plants in India. NMPB, New Delhi and FRLHT, Bangalore, India.
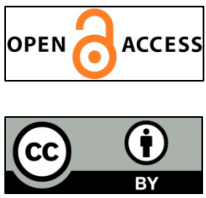

The journal offers free, immediate, and unrestricted access to peer-reviewed research and scholarly work. Users are allowed to read, download, copy, distribute, print, search, or link to the full texts of the articles, or use them for any other lawful purpose, without asking prior permission from the publisher or the author.

License - Articles published in Notulae Scientia Biologicae are Open-Access, distributed under the terms and conditions of the Creative Commons Attribution (CC BY 4.0) License.

(c) Articles by the authors; SHST, Cluj-Napoca, Romania. The journal allows the author(s) to hold the copyright/to retain publishing rights without restriction. 